${ }^{10}$ Netherlands Centre for Occupational Diseases, Coronel Institute on Work and Health, AMC/University of Amsterdam, Amsterdam, Netherlands

\section{8a EXPERIENCES AND LESSONS LEARNT IN THE PREPARATION OF LISTS OF OCCUPATIONAL DISEASES AND OF THE RELATED DIAGNOSTIC CRITERIA}

C Colosio. Department of Occupational and Environmental Health of the University of Milan, S. Paolo Hospital Unit and International Centre for Rural Health of the San Paolo University Hospital, Milan, Italy

\subsection{6/oemed-2018-ICOHabstracts.651}

According to ILO, an occupational disease is 'Any disease contracted as a result of an exposure to risk factors arising from work activity'. In most countries, a disease is defined 'occupational' when the national authorities acknowledge its occupational origin. The main tool available to national authorities to recognise the occupational origin of a disease are the lists, but aims, contents, structure and size of the lists significantly vary, from countries which have not any list to countries having lists composed of more than hundred groups of occupational diseases, therefore harmonisation is needed. A disease can be included in a list when the evidence of its link with exposure is strong, and solid diagnostic criteria exist. The main points for definition of diagnostic criteria are clinical features, occupational history and exposure, natural history and progress of the disease, and differential diagnosis. Other parameters are the minimum intensity of the exposure necessary to cause the disease and its minimum duration, the maximum latent period, that is the maximum time that can elapse from the induction or, as surrogate, from the beginning of exposure to the onset of the disease. Finally, the criteria of a minimum induction and the maximum disease-free period (from the end of the exposure to the onset of the disease) should be fulfilled. Unfortunately, these criteria cannot be guaranteed in condition mainly 'symptom based', such as low back pain, migraine, burnout, Karoshi. Also new diseases, diseases emerging from new risks or from new presentations of know risks deserve attention. Finally, the main properties of 'good' lists and criteria are credibility (involvement of experts and availability of references), consensus (among experts, employers, employees and governments), and consistency. These criteria and needs have been considered in the preparation of the document 'International Guidance Notes on the Diagnostic Criteria of Occupational Diseases'.

\section{8b OCCUPATIONAL DISEASES IN THE WORLD AND THE NEW ILO LIST}

S Niu. International Labour Organisation, Geneva, Switzerland

\subsection{6/oemed-2018-ICOHabstracts.652}

Introduction A recent study supported by the ILO indicates that 2.78 million deaths occur globally each year which are attributed to work. mortality due to work-related diseases accounts for 2.4 million $(86.3 \%)$ of the total estimated deaths. Yet many countries face a problem of no and under reporting on diseases caused by work. There is a high need to help the member states of the ILO to improve their national system on identification and recognition of occupational diseases.

Methods Description of the ILO activities on the identification and recognition of occupational diseases.

Results The ILO new list of occupational diseases revised in 2010 is being widely applied or regarded as a key point of international reference for countries who are updating their own national lists. To help member states in the detection of diseases caused by work, the ILO has organised a working group to develop guidance notes on the diagnosis of occupational diseases. This work is based on the national, regional and international practices on the identification and recognition of occupational diseases. The guidance notes will cover all the diseases included in the 2010 ILO list and be an important instrument for not only the diagnosis of occupational diseases but also their prevention, control as well as recording and reporting. This ILO work will also be harmonised with the WHO's work on occupational diseases in its ICD-11.The Guidance Notes will represent a major international effort in promoting the recording, reporting, prevention and control of occupational diseases.

\section{C THE ILO LIST OF OCCUPATIONAL DISEASES AND THE WHO ICD}

A Adisesh. Dalhousie University, Halifax, Canada

\subsection{6/oemed-2018-ICOHabstracts.653}

The International Labour Organisation (ILO) Governing Body during its 307th session in March 2010 approved the updated list of occupational diseases. The 2010 ILO list contains 106 items in four categories. The World Health Organisation (WHO) is a United Nations organisation, as is ILO, and produces the International Classification of Diseases (ICD) with the current version being the 10th edition in which there are 14199 codes. ICD serves as the international health information standard for collection, classification, processing, and presentation of disease-related data in national and international health statistics. ICD is being revised to better reflect progress in health sciences and medical practice. In line with advances in information technology, ICD-11 will be used with electronic health applications and information systems. The 60th World Health Assembly in 2007 endorsed Resolution WHA60.26 that requested WHO to determine international exposure and diagnostic criteria for early detection of occupational diseases and to include occupational causes of diseases in ICD11. An important aspect of agreement was that there would be partnership and joint action with ILO for implementation. Accordingly ILO established an expert working group for the purpose of determining exposure and diagnostic criteria for the list of occupational diseases. The work of this group has been complementary to that of the WHO working group on occupational health for ICD-11 revision and supported the inclusion of recognised occupational diseases in ICD-11. The ILO descriptions will be particularly relevant to physicians, regulators, compensation bodies and insurers, as well as to workers and their representatives. The ICD-11 will allow representation of these diagnoses with disease codes and will when fully populated also present epidemiologic, diagnostic and functioning information. These two developments therefore support common goals of disease recognition, notification and recording. 